\title{
Inkontinensia Urin Pascapersalinan dan Faktor-Faktor Risiko yang Memengaruhinya
}

\author{
Edy Fakhrizal $^{1 *}$, Sri WahyuMaryuni ${ }^{1}$
}

\begin{abstract}
Postpartum urinary incontinence is an important and often overlooked form of maternal morbidity. The aim of this study is to obtain prevalence of postpartum urinary incontinence and its influential risk factors. This is an observational study. The subjects were all primipara stayed in Obstetric \& Gynecology of Arifin Achmad Pekanbaru - Riau hospital, between July $1^{\text {st }}$ and December $31^{\text {st }} 2014$. The data of risk factors (demographic and obstetric) was obtained from medical records and cough test was done too. The data was analyzed with computerized statistic data analysis 12 ( Stata 12 ). The distribution of data were analyzed with descriptive univariate and presented in (n) and (\%). Bivariate analysis was done to see any influential risk factors to postpartum urinary incontinence event. The prevalence of urinary incontinence in this study was $30 \%$ and the influential risk factors were BMI, body weight changing during pregnancy, delivery mode, birthweight and length of second stage.
\end{abstract}

Key words: Postpartum urinary incontinence, prevalence, risk factors.

Inkontinensia urin merupakan masalah kesehatan masyarakat di seluruh dunia yang mempengaruhi kehidupan jutaan perempuan dan menyebabkan dampak sosio-ekonomi, fisik dan psikologis yang serius serta hambatan dalam hubungan seksual, yang secara keseluruhan akan mengakibatkan penurunan kualitas hidup, depresi dan menarik diri dari pergaulan. Inkontinensia urin dapat sangat merusak keadaan emosional perempuan yang menyebabkan hilangnya rasa percaya diri dan menyebabkan ketakutan berhubungan intim. ${ }^{1}$ Pada suatu studi dikatakan bahwa inkontinensia urin, penyakit Alzheimer dan stroke merupakan tiga penyakit kronik yang sangat jelek dampaknya terhadap kualitas kesehatan seseorang. ${ }^{2}$ Suatu riset menunjukkan bahwa perempuan begitu ketakutan atas kemungkinan menderita inkontinensia urin dikemudian hari, sehingga mereka mulai memilih persalinan seksio sesaria sebagaimana yang mereka dengar bahwa

\footnotetext{
* Penulis untuk korespondensi : Sub Bagian Uroginekologi, Bagian Obstetri \&Ginekologi Fak. Kedokteran Univ. Riau / SMF. Obstetri \&Ginekologi RSUD Arifin Achmad Pekanbaru. email : dredy_spog@yahoo.co.id
}

persalinan pervaginam dapat merusak otot-otot dasar panggul, yang selanjutnya akan mengakibatkan inkontinensia urin. ${ }^{3}$

WHO menyatakan bahwa inkontinensia urin merupakan masalah kesehatan yang cukup besar, diperkirakan lebih dari 200 juta orang di dunia mempunyai masalah dalam berkemih. ${ }^{4}$ Data dari the Healthcare Cost and Utilization Project menunjukkan bahwa kunjungan perempuan ke dokter, khususnya untuk berobat inkontinensia urin meningkat dari 845 per 100.000 kunjungan pada tahun 1992 menjadi 1.845 per 100.000 kunjungan pada tahun $2000 .^{5,6}$

Prevalensi inkontinensia urin pada perempuan berkisar antara 3-55\% bergantung pada batasan dan kelompok usia, ${ }^{7}$ bervariasi di setiap negara yang disebabkan oleh berbagai faktor.Pada suatu review sistematik, Thom dan Rortveit mendapatkan prevalensi inkontinensia urin pascapersalinan sebesar 33\%, setengahnya adalah prevalensiinkontinensia urin tekanan, didapatkan pula bahwa prevalensi inkontinensia urin tekanan dua kali prevalensi inkontinensia urin desakan. ${ }^{8,9} \mathrm{Di}$ Indonesia, prevalensi inkontinensiaurin yang sesungguhnya belum diketahui secara pasti, hal ini 
disebabkan banyak orang yang menganggap inkontinensia urin merupakan hal yang wajar setelah melahirkan dan kebanyakan perempuan merasa malu untuk memeriksakan diri kepada tenaga kesehatan. Diperkirakan pula adanya kecenderungan masyarakatuntuk berobat ke pusat kesehatan nonformal,menyebabkan banyak kasus tidak tercatat sehingga data yang ada menjadi kurang akurat. Kurangnya pengetahuan akan masalahgejala saluran kemih bawahmenyebabkan banyak sekali kasus gejala saluran kemih bawah yang tidak terungkap dan menjadi fenomena gunung es. Walaupun gangguan ini sangat mempengaruhi kualitas hidup, umumnya pasien tidak mencari pertolongan. ${ }^{10}$

Inkontinensia urin tekanan dan inkontinensia urin desakan merupakan dua tipe yang paling sering terjadi. Inkontinensia urin tekanan merupakan inkontinensia urin yang berhubungan dengan aktivitas fisik, didefinisikan sebagai keluarnya urin yang tidak terkendali saat beraktifitas, bersin atau batuk. ${ }^{11}$ Inkontinensia urin tekanan dan prolaps organ panggul adalah kelainan yang umum terjadi dan memerlukan operasi perbaikan pada $11 \%$ perempuanmenjelang usia 80 tahun, ${ }^{12}$ dengan kemungkinan operasi ulang sebesar $30 \% .{ }^{13}$ Kelainan ini berhubungan erat dengan persalinan pervaginam dan paritas yang mengakibatkan terjadinya disfungsi dasar panggul. ${ }^{13}$ Boyles dkk. memperlihatkan bahwa persalinanyang pertama memberikan pengaruh terbesar pada mekanisme kontinensia. ${ }^{14}$ Namun masih dipertanyakan apakah seksio sesaria dapat mencegah trauma pada dasar panggul. ${ }^{1,15-17}$ Tidak ada uji klinis yang telah dilakukan untuk menentukan bahwa seksio sesaria merupakan faktor proteksi terhadap terjadinya inkontinensia urin. Terdapat dua studi epidemiologi besar yang melaporkan hubungan inkontinensia urin dengan aspek-aspek kehamilan dan cara persalinan, ${ }^{4,18}$ kedua studi mendapatkan bahwa risiko inkontinensia urin lebih tinggi pada perempuan yang pernah melahirkan dibandingkan dengan perempuan yang belum pernah melahirkan, namun tidak dapat memperlihatkan efek proteksi seksio sesaria. ${ }^{17}$

Faktor-faktor risiko inkontinensia urin tekanan yang telah diketahui saat ini meliputi ras kulit putih, obesitas, kehamilan dan persalinan, terutama persalinan pervaginam. ${ }^{19-23}$ ENREF 11Studi lain menunjukkan bahwa inkontinensia urin saat antenatal, peningkatan indeks massa tubuh, pendidikan yang rendah dan persalinan pervaginam merupakan faktor risiko inkontinensia urin pascapersalinan. ${ }^{14,24}$

Penelitian tentang prevalensi dan faktor risiko inkontinensia urin tekanan pada perempuan sangat penting untuk menentukan strategi pencegahannya,mengingat besarnya masalah yang ditimbulkan akibat inkontinensia urin tekanan pada perempuan. Insiden inkontinensia urin tekanan yang menetap pada tiga bulan pasca persalinan merupakan faktor risiko yang signifikan untuk terjadinya inkontinensia urin di kemudian hari. Pada suatu penelitian dilaporkan bahwa perempuan dengan inkontinensia urin tekanan yang menetap pada tiga bulan pascapersalinan, $92 \%$ akan berlanjut menjadi inkontinensia urin tekanan pada lima tahun pasca persalinan. ${ }^{20,24,25}$ Oleh karena itu upaya identifikasi dini penyebabnya dan faktor risiko yang berperan serta kemampuan memprediksi timbulnya inkontinensia urin tekanan, menjadi sangat penting sebagai dasar pencegahan dan tatalaksana.

\section{METODE}

Penelitian ini merupakan studi observational. Subjek penelitian adalah semua primipara yang menjalani perawatan pasca persalinan di ruang rawat SMF Obstetri \& Ginekologi RSUD Arifin Achmad Pekanbaru - Riau selama periode 1 Juli - 31 Desember 2014. Pasien primipara yang memenuhi kriteria inklusi berupa kehamilan tunggal, usia kehamilan saat persalinan e"37 minggu dan BBL $\geq 2500$ gr dan bersedia ikut penelitian yang dibuktikan dengan menandatangani lembar informed consent, diminta mengisi lembar kuesioner inkontinensia urin QUID (The questionnaire for urinary incontinence diagnosis)tervalidasi bahasa Indonesia dalam pendampingan tim peneliti yang sudah diberikan pelatihan mengenai anamnesis dan pengisian kuesioner QUID. Penilaian QUID untuk inkontinensia urin tekanan adalah jika jawaban subjek untuk salah satu pertanyaan nomor 1,2 , dan 3 adalah 'ya'. Untuk inkontinensia urin desakan ditentukan jika jawaban subjek untuk salah satu pertanyaan nomor 4,5, dan 6 adalah'ya'. Untuk inkontinensia tipe campuran merupakan gabungan dari jawaban keduakelompok pertanyaan pada kuesioner QUID. Data pasien mengenai faktor risiko 
demografik (usia, berat badan sebelum hamil dan saat persalinan ini, tinggi badan) serta faktor risiko obstetrik (cara persalinan, lama kala dua, berat badan bayi saat lahir / BBL, dilakukan episiotomi atau tidak dan adanya robekan perineum atau tidak dan derajatnya) diperoleh dari catatan medik medik pasien. Kuesioner yang telah terisi diperiksa kelengkapannya oleh tim peneliti dan dilaporkan kepada peneliti setiap hari. Selanjutnya dilakukan tes batuk oleh peneliti. Uji batuk (cough test) dilakukan dengan terlebih dahulu menginstruksikan pasien untuk berkemih spontan dan diikuti dengan minum dua gelas air $(16 \mathrm{oz}=450 \mathrm{ml})$ sebelum dilakukan uji, dua jam kemudian uji batuk dilakukan. Pasien diminta untuk batuk keras dalam posisi litotomi. Uji batuk dikatakan positif jika tampak urin keluar dari meatus uretra eksterna. Jika hasil uji batuk dalam posisi litotomi tidak tampak keluar urin, maka uji diulangi lagi dalam posisi berdiri. Pada studi ini subjek dikatakan menderita inkontinensia urin tekanan bila pada lembar kuesioner QUID dijawab 'ya' untuk pertanyaan nomor 1,2 dan 3 sertauji tekanan batuk positif.Analisis pada penelitian ini dilakukan menggunakan program komputer. Sebaran data subjek penelitian akan diolah dengan analisis univariat deskriptif dan disajikan dalam $\mathrm{n}$ dan $\%$. Untuk melihat faktor risiko (demografik dan obstetrik) yang berpengaruh terhadap kejadian inkontinensia urin pascapersalinan akan dilakukan analisis bivariat. Nilai $p$ yang dianggap signifikan dalam penelitian ini ditentukan sebesar 5\%. Hasil analisis akan dilaporkan dalam bentuk frekuensi dan persentase nilai $p$.

\section{HASIL}

Subjek penelitian direkrut antara bulan Juni sampai dengan Desember 2014, sebanyak 447 primipara yang memenuhi kriteria inklusi dan eksklusi telah bersedia mengikuti penelitian ini, segera setelah persalinannya. Dari populasi ini, 134 subjek $(30,0 \%)$ diantaranya menderita inkontinensia urin (IU) dengan distribusi tipe inkontinensia urin sebagai berikut: 40 subjek $(29,9 \%)$ dengan inkontinensia urin tekanan (IUT), 50 subjek $(37,3 \%)$ dengan inkontinensia urin desakan (OAB) dan 44 subjek $(32,8 \%)$ menunjukkan inkontinensia urin campuran (mixed urinary incontinence), sebagaimana terlihat pada gambar1.

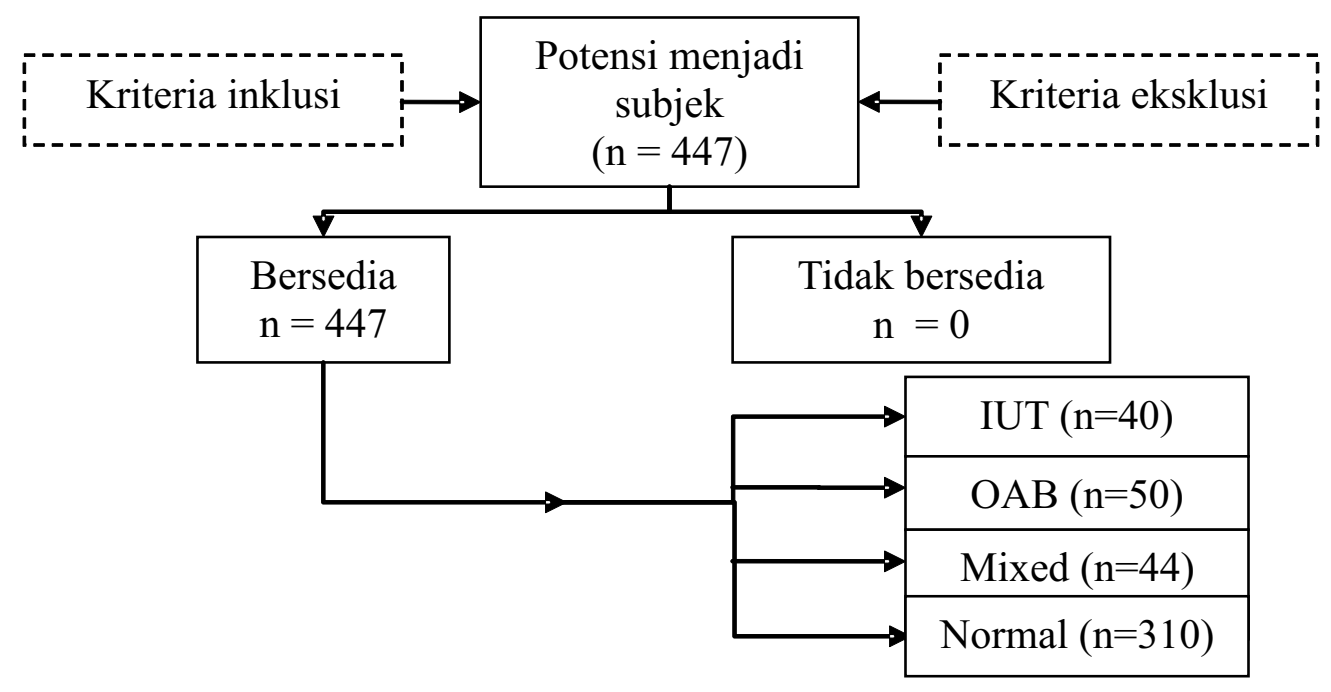

Gambar 1. Flow chart hasil penelitian

\section{Karakterisitik Subjek Penelitian}

Populasi subjek yang telah menyelesaikan pemeriksaan pascapersalinan memiliki karakteristik sebagaimana terlihat pada tabel 1 . 
Tabel 1. Karakteristik subjek penelitian

\begin{tabular}{lcc}
\hline Variabel & Kategori & Deskripsi \\
\hline Usia (tahun) & & $27,00(19,03-36,98)$ \\
Klasifikasi usia & $\geq 30$ tahun & $107(23,9)$ \\
& $25-29$ tahun & $217(48,5)$ \\
& $20-24$ tahun & $112(25,1)$ \\
IMT Hamil & $<20$ tahun & $11(2,5)$ \\
Klasifikasi IMT & & $26,65(20,31-37,24)$ \\
& 230 & $86(20,3)$ \\
Perubahan BB (kg) & $25-29$ & $210(47,0)$ \\
Klasifikasi perubahan BB & $<25$ & $151(33,8)$ \\
& & $13,00(6,00-24,00)$ \\
Episiotomi & $\geq 20$ kg & $26(5,8)$ \\
& $15-19$ kg & $118(26,4)$ \\
Robekan Perineum & $<15$ kg & $303(67,8)$ \\
Cara Persalinan & Ya & $152(34,0)$ \\
& Tidak & $295(66,0)$ \\
& Derajad 3-4 & $26(5,8)$ \\
Berat lahir (g) & Ekstraksi vakum & $421(94,2)$ \\
Klasifikasi berat lahir (g) & Spontan & $41(9,2)$ \\
& SS Darurat & $133(29,8)$ \\
& SS Terencana & $7(1,6)$ \\
Lama kala II (menit) & & $266(59,5)$ \\
Klasifikasi lama kala II (menit) & $\geq 3700$ & $3100(2500-3900)$ \\
Total & $3360-3699$ & $41(9,2)$ \\
& $3000-3359$ & $73(16,3)$ \\
& $<3000$ & $174(38,9)$ \\
& & $159(35,6)$ \\
& $>60$ & $13,17(0,00-240,00)$ \\
& & $24(5,4)$ \\
& & $423(94,6)$ \\
\hline & & $447(100,0)$ \\
\hline & &
\end{tabular}

Keterangan: Variabel numerik berdistribusi normal disajikan dalam rerata \pm SD

Variabel numerik berdistribusi tidak normal disajikan dalam median (minimum-maksimum).

Variabel kategorik disajikan dalam jumlah (persentase).

\section{Analisis Bivariat}

Untuk melihat pengaruh variabel bebas (faktor risiko) terhadap variabel terikat (IU) pada penelitian ini dilakukan analisis bivariat sebagaimana terlihat pada tabel 2 . 
Tabel 2.Analisis bivariat pengaruh faktor risiko terhadap IU pascapersalinan

\begin{tabular}{|c|c|c|c|c|c|c|}
\hline & & \multicolumn{2}{|c|}{ IU } & \multicolumn{2}{|c|}{ Normal } & \multirow{2}{*}{ Nilai $p$} \\
\hline & & $\mathrm{n}$ & $\%$ & $\mathrm{~N}$ & $\%$ & \\
\hline \multirow[t]{4}{*}{ Usia } & $\geq 30$ tahun & 35 & 32,7 & 72 & 67,3 & 0,440 \\
\hline & 25-29 tahun & 64 & 29,5 & 153 & 70,5 & \\
\hline & 20-24 tahun & 34 & 30,4 & 78 & 69,6 & \\
\hline & $<20$ tahun & 1 & 9,1 & 10 & 90,9 & \\
\hline \multirow{3}{*}{ IMT hamil } & $\geq 30$ & 39 & 45,3 & 47 & 54,7 & 0,002 \\
\hline & $25-29$ & 55 & 26,2 & 155 & 73,8 & \\
\hline & $<25$ & 40 & 26,5 & 111 & 73,5 & \\
\hline \multirow[t]{3}{*}{ Perubahan BB } & $\geq 20 \mathrm{~kg}$ & 11 & 42,3 & 223 & 73,6 & 0,048 \\
\hline & $15-19 \mathrm{~kg}$ & 43 & 36,4 & 75 & 63,6 & \\
\hline & $<15 \mathrm{~kg}$ & 80 & 26,4 & 223 & 73,6 & \\
\hline \multirow[t]{2}{*}{ Episiotomi } & Ya & 43 & 28,3 & 109 & 71,7 & 0,576 \\
\hline & Tidak & 91 & 30,8 & 204 & 69,2 & \\
\hline \multirow[t]{2}{*}{ Robekan perineum } & Derajat 3-4 & 12 & 46,2 & 14 & 53,8 & 0,064 \\
\hline & Derajat $1-2$ / tidak ada & 122 & 29,0 & 299 & 71,0 & \\
\hline \multirow[t]{4}{*}{ Cara Persalinan } & Ekstraksi vakum & 21 & 51,2 & 20 & 48,8 & $0,033 \mathrm{k}$ \\
\hline & Spontan & 26 & 19,5 & 107 & 80,5 & \\
\hline & SS darurat & 4 & 57,1 & 3 & 42,9 & \\
\hline & SS terencana & 83 & 31,2 & 183 & 68,8 & \\
\hline \multirow[t]{4}{*}{ Berat lahir } & $\geq 3700 \mathrm{gr}$ & 30 & 73,2 & 11 & 26,8 & 0,000 \\
\hline & $3360-3699$ & 36 & 49,3 & 37 & 50,7 & \\
\hline & $3000-3359$ & 41 & 23,6 & 133 & 76,4 & \\
\hline & $<3000$ & 27 & 17,0 & 132 & 83,0 & \\
\hline \multirow[t]{2}{*}{ Lama kala 2} & $>60$ menit & 14 & 58,3 & 10 & 41,7 & 0,002 \\
\hline & $\leq 60$ menit + SC elektif & 120 & 28,4 & 303 & 71,6 & \\
\hline
\end{tabular}

Variabel dengan hasil uji chi-square pada analisis bivariat dengan nilai $p<0,05$ dianggap berpengaruh terhadap kejadian inkontinensia urin pascapersalinan. Dari tabel terlihat bahwa usia ibu, episiotomi dan robekan perineum tidak berpengaruh terhadap kejadian inkontinensia urin pascapersalinan. Pada analisis ini didapatkan bahwa indeks massa tubuh (IMT), perubahan berat badan selama kehamilan, cara persalinan, berat badan lahir (BBL) dan lama kala dua berpengaruh terhadap kejadian inkontinensia urin (IU) pascapersalinan pada primipara sebagaimana terlihat pada tabel 2 .

\section{PEMBAHASAN}

Pada penelitian ini didapatkan 134 subjek $(30,0 \%)$ yang menderita inkontinensia urin segera pascapersalinan. Hasil ini lebih tinggi daripada yang didapatkan oleh Boyles dkk. tahun 2009 di Oregon, USA $(17,1 \%)$, namun hampir samadengan yang didapatkan oleh Glazener tahun 2006 di Scotland (29\%) ataupun hasil metaanalisis Thom \& Rortveit tahun $2010(28,7 \%)$.

Sebanyak 134 subjek yang menderita inkontinensia urin ini, 40 subjek $(29,9 \%)$ diantaranya menderita IUT, 50 subjek $(37,3 \%)$ dengan OAB dan 44 subjek $(32,8 \%)$ menunjukkan inkontinensia urin campuran. Berdasarkan distribusi tipe inkontinensia urin, hasil penelitian ini berbeda dengan studi Glazener tahun 2006 yang mendapatkan distribusi 48\% IUT, 22\% OAB dan $30 \%$ IU campuran, berbeda pula dengan hasil metaanalisis yang dilakukan oleh Thom \& Rortveit tahun 2010 terhadap banyak studi yang mendapatkan frekuensi IUT $46 \%$ dari seluruh IU dengan frekuensi rerata IUT lebih kurang dua kali lipat prevalensi rerata $\mathrm{OAB} .^{13}$

Untuk melihat pengaruh faktor risiko terhadap kejadian IUpascapersalinan pada primipara, semua 
variabel dilakukan analisis bivariat. Hasil analisis bivariat terhadap semua faktor risiko sebagaimana disajikan pada tabel 2 menunjukkan bahwa usia ibu saat persalinan, episiotomidanrobekan perineum tidak berpengaruhterhadap kejadian IU $(p>0,05)$. Pada studi Glazener didapatkan usia ibu $\geq 35$ tahun secara bermakna $(p<0,001)$ meningkatkan risiko kejadian IUT 3 bulan pascapersalinan dengan $O R$ 2,22 (IK95\% 1,47-3,33).

Pada penelitian ini didapatkan pengaruh IMT dan penambahan berat badan selama hamil terhadap risiko kejadian IU pascapersalinan $(p<0,05)$. Penelitian Boyle mendapatkan hasil yang sama, IMT $\geq 30$ saat persalinan meningkatkan risiko kejadian IUT dengan OR penambahan berat badan ibu selama hamil. Hasil penelitian ini dan beberapa penelitian sebelumnya dapat dijadikan sebagai bahan pertimbangan dalam memberikan saran dan edukasi untuk ibu hamil saat pemeriksaan asuhan antenatal $(A N C)$ tentang pentingnya mengubah gaya hidup dan mengendalikan berat badan (IMT) selama kehamilan, dalam upaya mengurangi risiko IUT di kemudian hari. ${ }^{18}$

Pada penelitian ini, didapatkan bahwa perbedaan cara persalinan berpengaruh terhadap kejadian IU pascapersalinan pada primipara $(p<0,05)$. Hasil ini sesuai dengan hasil penelitian yang didapatkan Boyles dkk. tahun 2009, kejadian IU lebih tinggi pada persalinan pervaginam dibandingkan pada seksio sesaria dengan OR 4,96 (IK95\% 3,82-6,44). Penelitian metaanalisis yang dilakukan oleh Thom \& Rortveit tahun 2010 mendapatkan kejadian IU lebih tinggi pada persalinan pervaginam (rerata 30,8\%) dibandingkan dengan seksio sesaria (rerata 14,8\%). Menurut Boyles, pengaruh buruk proses persalinan terhadap mekanisme kontinensia tampaknya terjadi pada saat penurunan bagian terbawah janin melewati vagina.Penurunan bagian terbawah janin ini akan merusak mekanisme kontinensia melalui trauma persarafan, kerusakan jaringan ikat ataupun trauma otot. $^{18}$

Hasil penelitian ini menunjukkan pula bahwa perbedaanberat lahir bayi berpengaruhterhadap risiko kejadian IU pasca persalinan $(p<0,05)$. Eftekhar dkk. mendapatkan berat lahir janin $3000 \mathrm{~g}$ akan meningkatkan risiko kejadian IUT pada 4 bulan pascapersalinan $\left(P=.000 ; \div^{2}=22,5\right)$. Penelitian
Glazener mendapatkan peningkatan risiko kejadian IUT pada berat lahir bayi $\geq 3700$ gdengan OR 1.56 (IK95\% 1.12 - 2.19). ${ }^{12}$ Namun, studi Boyles menunjukkan bahwa berat lahir bayi tidak berpengaruh terhadap risiko kejadian IU pada subjek yang dilakukan seksio sesaria, namun berat lahir bayi $\geq 4000$ gr pada persalinan pervaginam akan meningkatkan risiko kejadian IUT dengan OR 1,22 (IK95\% 1,03-1,45). ${ }^{18}$

Pada penelitian ini didapatkan pula bahwa risiko kejadian IU pascapersalinan dipengaruhi oleh lama kala dua yang dikategorikan $>60$ menit dan $\leq 60$ menit $(p<0,05)$. Boyle dkk. mendapatkan peningkatan risiko kejadian IU pada subjek dengan lama kala dua $\geq 45$ menit $(61,5 \%)$ dibandingkan subjek dengan lama kala dua $<45$ menit $(51,5 \%)$ dengan nilai $p<0,001$. $^{18}$

Hasil penelitian ini memberikan informasi yang penting bagi para pasien, klinisi dan pembuat kebijakan terkait pilihan cara persalinan dengan risiko kejadian IU di kemudian hari. Kepedulian yang lebih besar dari para klinisi saat melakukan asuhan antenatal untuk memotivasi dan memberikan saran pada ibu hamil dalam hal mempertahankan ataupun mengupayakan berat badan ideal selama hamil memberikan peran yang sangat besar bagi para ibu hamil dalam mencegah timbulnya dampak buruk inkontinensia urin tekanan terhadap kualitas hidup perempuan di masa depan. Hal inipenting mengingat sedemikian besarnya penurunan kualitas hidup perempuan akibat inkontinensia urin yang akan dideritanya kelak.

Mengingat bahwa hasil penelitian ini terbatas pada rentang waktu yang singkat (segera pascapersalinan), perlu dilakukan penelitian lanjutan yang menilai pengaruh factor risiko terhadap kejadian inkontinensia urin pascapersalinan pada rentang waktu yang lebih lama (3, 6,12 bulan atau lebih).

\section{KESIMPULAN}

Prevalensi inkontinensia urin pascapersalinan pada primipara pada penelitian ini adalah $30 \%$, adapun faktor-faktor risiko yang mempengaruhinya adalah IMT, perubahan berat badan selama kehamilan, cara persalinan, BBL bayi dan lama kala dua. 


\section{DAFTAR PUSTAKA}

1. Amaro JL, Macharelli CA, Yamamoto H, Kawano PR, Padovani CR, Agostinho AD. Prevalence and Risk Factors for Urinary and Fecal Incontinence in Brazilian Women.Int Braz J Urol 2009;35(5):592-7.

2. Schultz SE, Kopec JA. Impact of chronic conditions. Health Rep 2003;14:41-53.

3. DeLancey JOL, Morgan DM, Fenner DE, Kearney R, Guire K, Miller JM, et al. Comparison of levator ani muscle defects and function in women with and without pelvic organ prolapse. Obstetrics \& Gynecology. 2007;109:295-302.

4. Rortveit G, Daltveit AK, Hannestad YS, Hunskaar S; Norwegian EPINCONT Study. Urinary incontinence after vaginal delivery or cesarean section. N Engl J Med 2003;348:9007.

5. Thom DH, Nygaard IE, Calhoun EA. Urologic diseases in America project: urinary incontinence in women-national trends in hospitalizations, office visits, treatment, and economic impact. J Urol2005;173(4):1295-1301.

6. Carpenter DA, Visovsky C. Stress Urinary Incontinence: A Review of Treatment Options. AORN. 2010;91.

7. Jayna M. Holroyd-Leduc M, Sharon E. Straus M. Management of Urinary Incontinence in Women Scientific Review. JAMA 2004;291(8).

8. Bajuadji HS. Stres inkontinensia urin pascapersalinan. Jakarta: FKUI, 2004; 71. Tesis.

9. Thom DH, Rortveit G. Prevalence of postpartum urinary incontinence: a systematic review. Acta Obstetricia et Gynecologica Scandinavica. December 2010;89(12):1511-22.

10.Haylen BT, Ridder Dd, Freeman RM, Swift SE, Berghmans B, Lee J, et al. An International Urogynecological Association (IUGA) / International Continence Society (ICS) Joint Report On The Terminology For Female Pelvic Floor Dysfunction. Int Urogynecol J 2010;21(1):5-26.

11. Olsen AL, Smith VJ, Bergstrom JO, Colling JC, Clark AL. Epidemiology of surgically managed pelvic organ prolapse and urinary incontinence. Obstet Gynecol 1997;89:501- 506.

12.Memon HU, Handa VL. Vaginal Childbirth and Pelvic Floor Disorders Womens Health (Lond Engl). May 2013;9(3):1-18.

13.Boyles SH, Li H, Mori T, Osterweil P, Guise JM. Effect of Mode of Delivery on the Incidence of Urinary Incontinence in Primiparous Women. American College of Obstetricians and Gynecologists. 2009;113:134-41.

14. Chaliha C. Postpartum bladder dysfunction. Reviews in Gynaecological and Perinatal Practice. 2006;6(3-4):133-9.

15.Groutz A, Rimon E, Peled S, et al. Cesarean section: does it really prevent the development of postpartum stress urinary incontinence? A prospective study of 363 women one year after their first delivery. Neurourol Urodyn. 2004;23(1):2-6.

16.McKinnie V, Swift SE, Wang W, Woodman P, O'Boyle A, Kahn M, et al. The effect of pregnancy and mode of delivery on the prevalence of urinary and fecal incontinence. American Journal of Obstetrics and Gynecology 2005;193:512-8.

17.MacLennan AH, Taylor AW, Wilson DH, Wilson D. The prevalence of pelvic floor disorders and their relationship to gender, age, parity and mode of delivery. BJOG 2000;107:1460-70.

18.Thorp JM Jr, Norton PA, Wall LL, Kuller JA, Eucker B, Wells E. Urinary incontinence in pregnancy and the puerperium: a prospective study. Am J Obstet Gynecol 1999;181:266-73.

19.Rebecca G. Rogers MD. Urinary Stress Incontinence in Women. N Engl J Med 2008;358:1029-36.

20.Burgio KL, Zyczynski H, Locher JL, Richter HE, Redden DT, Wright KC. Urinary incontinence in the 12-month postpartum period. Obstet Gynecol 2003;102:1291-8.

21.Fritel X, Ringa V, Varnoux N, Fauconnier A, Piault S, Bréart G. Mode of delivery and severe stress incontinence: a crosssectional study among 2,625 perimenopausal women. BJOG 2005;112:1646-51. 
22.Keilman LJ. Urinary incontinence: basic evaluation and management in the primary care office. Prim Care 2005;32: 699-722.

23.Burgio KL, Borello-France D, Richter HE, Fitzgerald MP, Whitehead W, Handa VL, et al. Risk factors for fecal and urinary incontinence after childbirth: the childbirth and pelvic symptoms study. Am J Gastroenterol 2007;102:1998-2004.
24. Viktrup L, Lose G, Rolff M, Barfoed K. The symptom of stress incontinence caused by pregnancy or delivery in primiparas. Obstet Gynecol 1992;79:945-9.

25. Viktrup L, Lose G. The risk of stress incontinence 5 years after first delivery. Am J Obstet Gynecol 2001;185:82-7. 